\title{
HRM practices and Sustainable Competitive Advantage Evidence in National Bank of Bahrain
}

\author{
Dr: Ibrahim Mohammad Hatamleh \\ Business Administration Department, College of Administrative Sciences \\ Applied Sciences University (ASU) Bahrain \\ Email: Ibrahim.hatamleh@asu.edu.bh
}

\begin{abstract}
The main purpose of this paper is to investigate how the HRM practices create a competitive advantage in the National Bank of Bahrain as a case study, from the perspective of the workers on the Bank. Thus data were collected from a randomly sampled respondent consist of 168 managerial employees of nine sub-bank locals in Bahrain through using a well-structured questionnaire, and validity and reliability to a questionnaire have been tested. descriptive and analytical methods were used, in addition, the Pearson correlation coefficient and simple linear regression test and Unilateral variation analysis (ANOVA). A key question measured in this research to explore how HRM practices which identified in five main factors (as planning and Job Analysis, and Recruitment and Selection, training and development, and Compensation (Pay and Benefits) seek to gain competitive advantage. The findings showed that there is a statistically significant effect of the dimensions of human resources management practices on achieving considerable a competitive advantage in the National Bank of Bahrain
\end{abstract}

Keywords

Competitive Advantage, HR Practices, Recruitment and Selection, training and development, Compensation.

\section{Introduction}

Today, business organizations are seeking to a compete in a complex environment witnessed rapid changes and huge challenges including the emergence concept of competitiveness, Free Trade Organization, and the liberalization of markets, besides organizations' transformed thoroughly for using technology and information system in their services as result of rapid technological developments, A. Scherer, G. Palazzo, and D. Seidl (2013).In order to work in this Non-monotonous environment requires using of strategic and HRM practices so as to understand the aspects and factors to create highnormal rates of competitiveness. Based on that, Organizations should have to pay attention to improve their procedures, policies and administrative methods, so as to carry out the activities, and accomplish their functions in efficiently and professionally way which enable organizations to enhance their organizational capacities and HRM practices to achieve competitiveness of the organization. According to, T. Wheelen and D. Hunger (2012), HRM practices are one of the management systems where benefits are realized for both individual and organization, through the best use of human resources practices. Human Resources form one of the most valuable asset of any organization, as all succeed plans are implemented by its employs, who has characterized technically, professional and cognitive skills, and has the ability to acts efficiently and professionally way, including the business, services quality, and the time needed to perform to reach the desired objective. In such situation in which the HRM practices are constructive positive and the staff serve as a source of competitive advantage and participate in the growth of organization's sustainable competitiveness and its sustenance. Organizations therefore need to invest continuously in the use of and employing knowledge, skills, motivation, staffing, selection, training, development and continually seeking to improve and implement better HR practices. Walter Wriston quoted well, "If you have the right person in the right place, you don't have to do anything else. If you have the wrong person in the job, the consequences will be very bad and no known human management system can save you." (Porter, 1985). 
Therefore, organizations need to continuously invest in employing knowledge, skills, motivation, staffing, selection, training, development and continually seeking to improve and implement better HR practices. Walter Wriston quoted well, "If you have the right person in the right place, you don't have to do anything else. If you have the wrong person in the job, the consequences will be very bad and no known human management system can save you." On the light of this, Companies have perceived that in today's competitive business environment, the quality of workforce one employs will make big difference in trend of its goals.

Based on the above, the modern management tendency a line with sustainable competitive advantage going to gather with the growing interest in HRM practices, which represent a comprehensive HR strategy of an organization. Organizations should focus on competent and committed workforce whom will be more satisfied and then higher performance; this will give the organizations a chance to develop its competitive edge. Also, organizations could successfully improve and develop HRM practices for a sustainable competitive advantage. Such practices comprise of HR planning, effective training, reward system, selecting highly skilled manpower; and Polarization and selection. These types are positively interrelated with the sustainable competitive advantage conception. Researchers mentioned that these four types of HRM practices could support an organization to achieve sustainable competitive advantage in a complicated milieu ((Dessler, 2015), (Barney, J. 1991), ( Muhammad A.Q., 2015). According to this, there must be a correspond between organization's competitive strategy and HRM practices. So organization has to boost its attention to both human capital advantage and human process advantage (learning, behavior, collaboration and so forth). Because the qualified, professional, committed, and dedicated employees with higher performance results are more satisfied, comfortable and contribute to less injuries, accidents, and thus boosting productivity, minimize labour turnover and clearly better customer service and satisfaction. Therefore, there is significance and vital need to study and check this aspect in sharp competitive environment particularly in in finance service milieu as the Banks and private financial institution. Hence, the aim of this research is to investigate the effect of the four types of HRM practices on sustainable competitive advantage in the private Jordanian hospitals located in the center of Amman

\section{Literature Review}

2.1 Human Resources Management Practices:

\subsubsection{Human Resources Management Definition}

Defining human resource management (HRM) needed clarifying of both the terminology of HRM and the definition of management concepts. Human resources are considered the basic feature of every company that is responsible for the people division affairs of the organization. As it's a duties are to select and employ for qualified people, training them, so as to increase their efficiency and improve their skills throughout studied training programs, training and educating them, helping them work in the best possible way, and providing with processes and mechanisms to ensure that these employees retain their successful relationship with the organization Whereas management has been described as effectively achieving the organization's objectives through its employees. Management of human resources (HRM) is a management method for individuals in every organization. Individuals are seen as key to success. It is concentrated on the employee characteristics of the management process in the organization. Scott, Clothier and Spriegel (2007) defined HRM as the part of management responsible for focusing on those areas of operations that are primarily concerned with the management relationship with employees and with individual and group growth. HRM is in charge of maintaining good employee relationships within the organization. It is also responsible for improving and enhancing the workforce ability and achieving alignment of the company's goals with those of its employees. Tripathi, P.C. (2002) 
defines HRM as the recruitment, selection, training, development, utilization, compensation, and motivation of human resources by the organization. Whereas Parry.E, \& Tyson. S. (2008) defines HRM as "Process that analyzes, handles, and manages the needs of the HR in organizations, with the purpose of achieving the strategic goals" and "the policies and activities incorporated in the performance of the managerial role -people-or HR aspect of, including recruitment, screening, training and appraising" (Dessler,2007).

\subsection{The significance of Human Resources Management\& its role}

The HRM role of the organization is centered on the workers, and assist the organization to handle its employees efficiently during the different stages of the recruiting process to achieve sustainable competitive advantage. These employment cycles starting within preselection, selection, and post-selection, these stages include planning and job analysis practices, preparation and job selection activities, and the organization should assess and determines what kinds of jobs are possible to exit in the upcoming period and locate what qualifications and skills are required to perform those jobs. Then. And ultimately selecting those who are deemed to be the most eligible.

The organization designs develop and implement HRM strategies to increase the levels of performance and to enhance and improve the efficiency and satisfaction levels of the employees of the organization by improving their awareness and providing them with the key skills required to do their jobs effectively by creating conditions that direct employees' efforts towards achieving the organization's objectives. In addition to the compensation practices and benefits that enable an organization to keep competent and loyal manpower at an affordable cost towards achieving the organization's goals, and ultimately acquiring a sustainable.

Many studies have been carried out to determine how organization could gain and maintain a competitive advantage, and most of these studies stated that this could be achieved through one of most significant Key assets of which the i.e. Human Resources. In this regard, Schuler (1984) identified key HRM activities such as Human resource planning; recruiting including training and development, selection, socialization; appraisal; and remuneration; and these practices needed to be followed and conducted efficiently and effectively through human resources management. Hence, HRM is responsible for recruiting competent and qualified employees, retain them, training them, and motivated them to perform at best effort, and providing with plans and rules to ensure that these employees maintain their productive affiliation with the organization, the results lead to sustainable competitive advantage. (Faugoo, 2009) indicated that the capability to entice the talents select the best, improving and developing skills, and encouraging innovation and retaining the competent employees will be the main key practices for an organization's success in today's global milieu. She studied that management of people greatly attached with the competitive advantage and HR practices are highly positively associated with Organizational performance. Whereas Huselid (1995) studied HR practices of high performance companies and found that enticing and selecting the right employees increase the employee productivity, support organizational performance, and take part in reducing turnover. And reached that the top four efficient HRM practices are recruitment and selection, training and development, contingency and reward system, and performance management, widely used by various researchers. 
Huselid (1995) has identified the relation between HRM practices and turnover, productivity and financial performance, and stated that the work practices have a high effect on organizational performance. While Harel, G.H. and Tzafrir, S.S. (1996) emphasized that HRM practices, especially selection and training, have deep associated with profit and nonprofit organizations' performance. Similar results are reached by Katou, A., and Budhwar, P. (2006) who found a positive effect of HRM practices on organization performance. While Pfeffer (1994) put out sixteen of HR practices consist of, Employment Security, Employee ownership, Incentive pay, Participation and empowerment, Symbolic egalitarianism, Selectivity in recruiting, Teams and job redesign, Long-term perspective, Wage compression, Measurement of practices, Cross utilization \& cross-training, High wage, Information sharing, Training and skill development, Promotion from within, Overarching philosophy. Training and skill development, Promotion from within, overarching philosophy, and indicated whether if these practices have applied in the right method from manpower could lead to achieve Sustainable competitive advantage in organizations. whereas (SOM, 2003) explained that in order to keep up with the environment variables, an organization must redesign human resources functions, and he pointed out that competitive advantage through manpower and culturally cultivated human resource practices are not difficult to attain but once achieved, it may be difficult to maintain, and it will not be easy to replicate.

HR planning helps managers to foresee and meet the organizations' needs related to the procuration, and use of their employees. The organization first develops a comprehensive plan (generally called a strategy). Then, through a process called demand and supply forecasting, it identifies the number and sort of staff required to carry out recruitment, selection, and training. Job analysis is a regular procedure for collecting, analyzing, and documenting certain jobs. The analysis determines set of dimensions related to what each worker does, the working circumstance and the qualifications of the workers, which are essential to do and perform the job successfully. Else, Job analysis information is roughly used to plan and coordinate HRM practices, such as training and development planning is an educational experience that teaches employees how to carry out their present or future jobs effectively. Training concentrate on current jobs, while development intended in preparing employees for potential future jobs. Training and development practices are typically drawing to improve organizational performance by reinforcing the knowledge and skill levels of employees. Benefits and incentives are a kind of compensation given to employees in addition to their salaries, such as health insurance or employee discounts. The goal of compensation practices is to assist and support the organization to create and maintain qualified and loyal manpower at a reasonable cost, (Walker,J.W.1980).

Most HRM researchers like Dessler (2015), Nehles et al,(2006), Lee and Bruvold (2003), Masoodul et al, (2013) and Yingying (2017), set some of the challenges affect HRM as shown below:

\section{Recruitment and Selection}

Recruitment is the process of completely filling the offered work positions, and provided with qualities and characteristics of appropriate sufficient number of candidates as well as fulfilling the organization's standards and requirements of jobs. Recruitment uses the job analysis to select and identify the organization's needs and requirements and is based on the organization's adopted strategy through human resource management planning (Shen, J. \& Edwards, V., 2004) 
Recruitment and selection are essential factors affecting an employee's efficiency. Recruit and select appropriate staff for the right work positions that have close relationships and positive connections for improving and developing the organization. Several studies results have manifested an affirmative relationship between recruitment and selection and employee performance, confirmed that applying recruiting and selection practices in a scientific method, could make good quality of talent and skills in the company. He also emphasized the importance of orientation and training as a supplement to the recruitment and selection processes by which the organizational culture and employees' attitude and their behavior can be aligned to create sustainable competitive advantage (Bowra, Z., et al, 2012)

Usually, Organizations built recruitment policies upon the organization's overall strategy. Because there are many dimensions that could influence the recruitment process and can be divided into internal and external factors, and that may impose a limitation by the government and market of labor, which could weaken the improvement of the process of recruitment policies. But, the Organization's policy and vision and professional HR managers overcome these restrictions, and after that, they could identify and select the right employees for the right work position. Thus, Selection and recruitment are considered one of the most important elements of HR practices, because the selection of the employee has close ties and interactions with the growth of the company. So, the selection is depending on gathering information and details about the candidates to decide who is suitable and who should be employed for each job (Marques, J. 2007).

Many studies have determined a good relationship between recruitment and selection and worker performance. Bowra. Z, et al, (2012) emphasized that by means of adopting practices recruitment and selection in a high-quality method, it allows keeping the right professional talents, and good quality of skills in the institutions He also stressed on the significance of training and education as supporting complement of recruitment and selection practices by which the organizational subculture and worker attitudes can be aligned to create advantageous results towards Sustainable Competitive Advantage.

\section{Training}

Most organizations seek to develop their employees, so after the recruitment and selection stage, the organization launches their training programs to train their employees, especially after conducting the orientation process. Training is the process of enhancing and increasing the skills, capabilities and knowledge of employees, that qualifying employees to perform their business with a high level of efficiency and effectiveness, and enable them for doing a particular job. Thus training process molds the thinking of employees and leads to high quality performance, and it is continuous process and never ending in competing organizations. Training is an attempt to change people's behavior by having them use different methods and means to do their work effectively. Changes in employee behavior include changes in knowledge, information, concepts, values, attitudes, skills and abilities (Lee and Bruvold, 2003).

\section{Training and development}

It involves identifying and evaluating employee training needs in order to develop the expertise and competencies that the organization needs in order to fulfill the current and future tasks. Training and development are planned and organized learning experiences that buildingcapacity staff and teach them how to do their current or coming jobs in an effective way. Thus, Training concentrates on current works and jobs, while development does develop and preparing 
employees for a potential future jobs. Training and development exercises and activities are also designed for improving employees' knowledge and skills levels, which enable them to accomplish their works towards reaching the organization's goals, and then built organizational performance in efficiently method, (Elnaga, A, \& Imran, A. 2013)

\section{Compensation}

The company sets salaries and benefits according to specific criteria and aims to promote justice, equality and equity,, based on consistent and a clear Compensation strategy, will influence the employer's ability to recruit new employees, gain employees satisfaction and loyalty and ensure maximum leverage of performance to meet organization objectives and the purposes and goals of the workers at the same time-it can influence the employer's ability to attract new applicants, achieve employee loyalty and ensure optimum leverage of performance power to meet organization objectives and at the same time it has an influence to attain the employee's objectives Hence, compensation is compensation that employees can earn due to their services. Therefore, compensation is what workers receive as a result of their good performance and distinguished services. So, the compensation cycle that organization adopt is divided into direct financial compensation and non-financial compensation, but regardless of whether the compensation is financial or non-financial employees needed to do the best in order to achieve the organization's goals, (Lee, K., \& Carter, S. 2011), (Lee, K., \& Carter, S. 2011)

Compensation requires payment and benefits. The term "wage" refers to the wage or salary that employees earn, and advantages are a kind of model of compensation offered to employees besides their salaries, such as health insurance or employee recoup. The goal of compensation practices is to assist and encourage the organizations to create and keep qualified and loyal manpower at a reasonable cost.

\section{Incentives and benefits}

According to, Diefendorff and Chandler (2011). Incentives are a set of process and methods that encourage and motivate employees to pay attention to accomplish work and achieve in terms of quality and quantity as required. Whereas, Maha (2015) indicates that Most companies recruit the most qualified and skilled employees, and the significance is in retaining the more efficient loyal and productive employees, and then enhance their loyalty, in order to do so, the companies provide a "package" that includes compensation (money), incentives (special benefits or rewards for good work), and benefits (valuable options such as health insurance and paid holidays. Because each employee is unique, and represents one of the most important asset pushing the organization to achieve a Competitive Advantage, so larger corporations offer a mix of variety incentives that fulfill the individuals' needs. In addition, the organizations are likely seeking to maintain a distinct and attract a skilled and well-trained workforce. Therefore, they must be retained, and given an attractive benefit, as financial benefits and healthy environmental and social working conditions, as well as other internal and external rewards that enhance employee loyalty for retention (Masoodul et al., 2013; Eric Ng C.H.E., \&others, 2012)

\section{Organizational culture}

Organizational culture is set of values and believes, includes the assumptions and expectations of the organization, its experiences, philosophy and beliefs shared by employees and framed in accordance with the organizations' rules, conduct and performance of the. In addition to that, the values guide the members' behavior and direct them how to act and make decisions. 
Culture basically relies on common attitudes, beliefs, customs, and written and unwritten rules that have been developed over time to do and carried out at organization environment in a good manner, which reinforce the organization to accomplish tasks and achieve its goals and strategies. In this topic, Human resources management is utmost essential to create a supportive and motivating organizational culture leads to effective performance and creative work, this can achieve through the training and development programs (David et al., 2015).

\section{Planning Job Analysis}

The purpose of this function is to provide the right type of workers to the organization, at the right time and place. This job gives a clear vision for an overview of the current and future of potential HR needs. In light of this, The HR planning and job analysis, determine the nature and form of potential workload, and the means, and techniques, of criteria of selection. Planning aims to improve and incubate long and short strategies term related to the requirements of the workforce. So, the HR planning assists managers to address and matches the changing needs regarding having its employees, through a set of a process called demand and supply prediction, it could estimate the numbers and type of staff needed to successfully implement its strategic plan. Also, this information enables the company to identify its plans' requirements regarding to selection, staffing and orientation, and training within its strategies.

\section{Job analysis}

Job analysis is a technical system for collecting, analyzing, and documenting information on specific jobs. The analysis determines what each employee does, the conditions of the work environment, and the employee's qualifications necessary to successfully perform the task. Therefore, most organizations to do apply the Job analysis information so as to build their strategic plans and coordinate all HRM practices, including the followings:

1. Identifying job qualifications for employment purposes.

2. Choosing the most adequate techniques for selection.

3. Upgrading and update of training programs.

4. developing a performance evaluate model.

5. Help to determine salary and income rates.

6. Putting performance criteria for productivity improvement and developing programs.

\section{Planning and career development}

A Career Development Plan is a personalized strategy, as written list of the short and long-term goals, to assist employees in achieving their career goals have pertaining to their current and future jobs, and should incorporate that employees' strengths and future career aspirations. (Bakker and Demerouti, 2008).

Further, Nehles et al (2006) emphasize that, career planning is generally aims at fulfilling the following objectives:

- -- By offering careers, not jobs, it provides and maintains appropriate human resources in an organization.

- Creates a climate environment an able of productivity, development and effectiveness.

- It maps out careers of different categories of workers, in accordance with their capacity and willingness to be 'educated, developed, and grown' to take the responsibility for higher posts.

- It seeks to preserve steady and a stable manpower within an organization by minimizing absenteeism and reducing employee turnover.

It caters the Organization's current and potential human resource needs where necessary, and at appropriate time. 


\section{HR development}

Yingying (2017) indicated that Human resources development (HRD) is one of the most important organizational activities, and it is an organizational framework supplied by organizations to increase and helping workers improve their employees' personal and organizational skills, expertise and skills, knowledge, and abilities of their employees, and one of the most significant opportunities that employees try to continue to strengthen their talents, abilities and motivation. Human Resource Development cover such opportunities as employee training, employee career development, performance management and development, coaching, mentoring, succession planning, key staff identification, and organizational development. The focus of all aspects of Human Resource Development is on developing the highest level of workforce to enable the organization and individual employees to accomplish their customer-service work objectives.

In most organizations (HRD) process begins upon the recruitment of new employees, and it continues with the organization throughout the work of that employee. Human resource development is designed to provide employees with the information they need to adapt to the culture of that organization and to do their jobs effectively. Development and training are aimed at making employees even better at what they do.

The above studies mentioned the human resources model, which aimed to help companies manage their workforce in the most efficient and effective manner possible, in order to achieve the established objectives. Where HRM play vital role to the organization and meet sustainable resource standards so as to achieve competitive advantage. For this, we conducted this study that demonstrates how we can attain the sustainable competitive advantage through HR practices of an employees' perspective in the National Bank of Bahrain.

\subsection{Sustainable competitive advantage}

In 1985 the term Sustainable Competitive Advantage (SCA) arose through the concept of low-cost or through distinction. And 1991 this term was described as a strategy adopted by a current or potential competitors' companies to create value for its products, goods, and services that are introduced aimed to double the benefits of this strategy. Upon this, we can say the competitive advantage could attain and subsist when a certain company consistently outperforms of other companies working in the same kind of products sort. A company is considered to be outperforming, and superior to others if profits are higher than the profits of other companies. Hence, the competitive advantage is thought to be stronger when it lasts for a long-term period of time, this give the companies more space and be able to achieve a sustainable competitive advantage and preserve it for many years (Barney, 1991). In the same way Hoffman (2000), Saw that higher-level skills and higher resources could also lead to maintain a sustainable competitive advantage. Hence, companies can gain a sustainable competitive advantage by integrating skills and resources in specific and lasting ways, and by focusing on actively learning how to align the efforts of all workers to promote the development of particular core competencies which do vital role in participating to gain a sustainable competitive advantage

- According to Al-Saadi (2006), a competitive advantage does mean that the organization is able to conduct and perform its work in a manner that's impossible for its rivals to emulate and imitate. The organization thus are able to achieve a competitive advantage by 
creating jobs that make value within the areas of cost reduction in competition with its rivals or by focusing on its results in ways that contribute to success, and lead to excellence and reduce costs, and achieving distinction from others. That may be accomplished by means of the subsequent:

- Superior Efficiency: Relates to cost of input required to produce specific and different outputs, with high productivity superior and high quality compared to competitors.

- Superior quality: measured by what the organization's products and services achieve in terms of customer acceptance, the level of performance of these products and services, and the high quality that contributes to the creation of a reputable brand name, reduces the effort and time needed to fix product defects.

- Superior Innovativeness: Achieved by introducing a new service, product or working in a style different from that of competitors.

- Superior Customer Responsiveness: Requires a good and accurate knowledge of customer needs first, then concentrate on those needs with a high level of quality which is difficult for rivals to achieve (Sheik, 2004,68)

Competitive Advantage is a set of rules and conditions that enable the company to produce a high quality productions or service at an equal value, at a lower price, and a more attractive and convenient style. These distinctive features allow companies to sell more than their competitors in the market. Sustainable competitive advantage is the long-term benefit correlated with the carried out of a unique value-creating strategy, firm has a sustainable competitive advantage when it gains some high qualities or attributes which are different from other competitors in the markets environment and makes it outstanding in their products. When the appropriate competitive advantages last for several years, then it's called as sustainable competitive advantages. Here it is very important for companies to maintain sustainable competitive advantages in current competitive climate, which can be measured by looking at the company's profits that should be more than its competitors in the business environment.

The company's essence competence is form the only thing a company can do in a better manner than its competitors. Competitive advantages are referring to a different dimension that includes a comprise of cost body, branding, the quality of product offerings, the distribution network, and customer service, and concentrate on research and development, manpower capabilities, development and innovation. Thus, Competitive advantage as a term is clearly defined as anything that gives an organization a benefit, a merit and value over their other market competitors. (Porter, 1998).

Hit, Ireland and Huskisson (2009) Noted that sustained competitive advantage is achieved when competitors in firms are unable to replicate the advantages of an organization's strategy approach, and do not have enough appropriate resources to mimic. Besides including capabilities, competencies, and distinctive competencies flexibility, innovation, high performance, raise productivity and personal customer service are sources of sustainable competitive advantage. So, capabilities, in particular, are the key aspects that deploy resources and turn it into final products and services K. Hafeez, Y, et al (2002). Afterwards, a set of these strengths must be integrated and transformed into competencies, and skills to make them more valuable, more important, and more relevant in terms of delivering benefits for customers and offering new types of products (Lado, A. Wilson, M. 1994). According to O'Reilly and Pfeffer, (2000), "We 
live in a world where knowledge intelligence is increasingly so important, rather than physical resources, we need intelligent, and smart staff who can do considerable, and significant things to increase productivity, and improve profitability, develop new products and services and do it more quickly. The above researchers' studies refer to a model of competitive advantage towards human resources. Due to this, human resources are one of the most important assets of the organization that could grow and participate to the organization to match and meet of sustainable resource standards to develop and achieve sustainable competitive advantage. But the studies that we have studied were below expectations on how to develop a competitive advantage. so, we conducted this study to show how we can gain competitive advantage through HR practices from an employee's point of view at National Bank of Bahrain.

\subsection{Integration between human resource practices and the competitive advantage.}

There are many reasons that have highlighted the importance of human resources as a source of competitive advantage in organizations. As Human resource management practices affect the various activities of the organization and interact and integrate with each other for the purpose of implementing the plans of the institution and its stated objectives, and therefore they play an important role in achieving the enterprise's competitive advantage. And there is a link and integration between the human resources management and the general strategy of the institution, in order to achieve a competitive advantage and work to maintain it. By continuously focusing on renewable and creative human resources, achieving efficiency in its various functions, commitment to high quality, achieving customer wishes, expectations, and delivery within the specified deadlines. With these specifications, they are able to respond to the highly changing competitive. In this regard, most studies in the field of business administration indicate that the institution's ability to compete is linked to its future success in business, which is subject to rapid ways to reach future opportunities, not current opportunities. This can be embodied through the pivotal competencies, that represent a combination of skills and technologies that contribute in an explanatory way to the added value of the final product stage (Fattler,M, 2009). In light of this relationship between human management practices and the strategy of the organization, human resource management practices are not carried out in isolation from the strategy of the organization as a whole by making the human component a critical element in the development and execution of the organization's key decisions, That results in effective individual and organizational outcomes, including improving and enhancing the organization's competitive advantage (Fattler,M, 2009). In this regard, mention of literary studies mentioned that most of the interested researchers in the area of the HRM practices, recommended to nominate the right person for correct, and proper jobs, the adequacy and appropriateness of and the coaching programs with the apprenticeship work that affects at the performance. And via that, the HRM Practices will have significance effect on achieving a competitive advantage (Bo Hansson, 2007).

\section{Study Objectives}

The study seeks to gain the following objectives:

- Investigate the HRM practices on achieving the competitive advantage.

- Verifying how the Jordanian National Bank acquired a sustained competitive advantage through its employees.

\section{MODEL STUDY}

To conduct the study, this model illustrates the following dependent and independent variables. 
Fig. 1: Shows the research framework

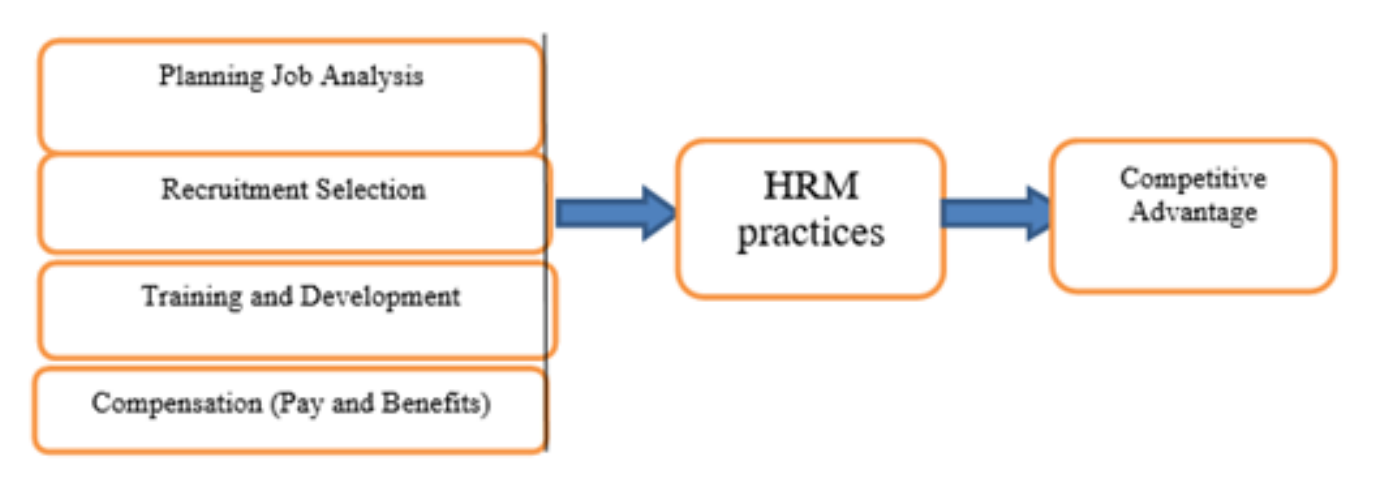

\subsection{Hypotheses of the study}

The study hypotheses were developed and formulated in accordance with the study problem and its significance, and based on the above conceptual framework that it attempts to attain its objectives by testing the following hypotheses:

\subsubsection{The Hypothesis}

H1: HRM Practices affect the achievement of a competitive advantage in the National Bank of Bahrain

H2: Planning Job Analysis affect the achievement of a competitive advantage in the National Bank of Bahrain

H3: Recruitment Selection affect the achievement of a competitive advantage in the National Bank of Bahrain

H4: Training and Development affect the achievement of a competitive advantage in the National Bank of Bahrain.

H5: Compensation (Pay and Benefits) affect the achievement of a competitive advantage in the National Bank of Bahrain

\section{Research Methodology}

Descriptive analytical method was used to describe the variables. A field survey method (questionnaire) was used to collect data. The study used quantitative way to locate answer of the research questions of this study by analyzing of the quantitative data. Richards \& Schmidt, (2002) said that qualitative research methodology can help researchers deal with field work without adhering to any predefined categories of analysis. The logical basis behind the design selection was that it helped researchers explore the current state of HRM practices on Sustainable Competitive Advantage at the main National Bank of Bahrain.

The target population of this study is consisting with all the managers and managerial employees at the head offices of National Bank of Bahrain, which were 70 persons, with reference to National Bank statistics in in 0'ctober 2020. The study was conducted on all employees surveyed of National Bank, this figure represents all the target society. A well-structured questionnaire was built and distributed to 70 of National Bank employees. The returned total questionnaires valid representing $100 \%$ response rate of the sample. The questionnaire was validated and reliable, by verifying the comments of the arbitrators. And by analyzing the Statistical Package of Social Sciences (SPSS), by using Pearson correlation coefficient for the adoption of internal consistency and Cronbach Alpha Equation for the stability of 
internal consistency. So, the result showed that Pearson's Correlation Coefficient for internal consistency for all variables was between 0.742 and 0.885 . Also, it pointed out that the Cronbach's alpha for all variables was ranged between 0.762 and 0.924. For that, considering that the questionnaire's validity and reliability and the internal consistency reliability of the measures using in this study can be considered accepted. According to above, according of that, the results provide proper and acceptable points of the characteristics of the scale that allows use in this study.

\subsection{Measurement Tool}

$\underline{\text { Data Analysis Techniques }}$

Table1. The Alpha Cronbach Coefficient of the Variables Study

\begin{tabular}{|l|c|c|}
\hline Variable & $\begin{array}{l}\text { Paragraph } \\
\text { No }\end{array}$ & $\begin{array}{l}\text { The value of } \\
\text { Alpha } \\
\text { Cronbach }\end{array}$ \\
\hline Planning Job Analysis & 7 & 0.785 \\
\hline $\begin{array}{l}\text { Recruitment } \\
\text { Selection }\end{array}$ & 8 & 0.842 \\
\hline $\begin{array}{l}\text { Training and } \\
\text { Development }\end{array}$ & 12 & 0.924 \\
\hline $\begin{array}{l}\text { Compensation (Pay } \\
\text { and Benefits) }\end{array}$ & 10 & 0.762 \\
\hline $\begin{array}{l}\text { Competitive } \\
\text { Advantage }\end{array}$ & 9 & 0.843 \\
\hline All Variables & 46 & 0.953 \\
\hline
\end{tabular}

According to Table 1, Alpha Cronbach coefficients are reliable and statistically represented, so the values were between (0.7620.924), the highest one is "Training and Development", but the lowest is "Compensation (Pay and Benefits)". Alpha Cronbach coefficient of instrument reached to (0.953) which is high and accepted; make it valid for applying purposes. The quality of measure is included when the Alpha Cronbach value exceeds (0.60). (Sekaran, 2010). Which indicates a high internal consistency reliability for the scale used. Consequently, the items under the scale are measuring the same construct, and thus the scale used is high reliable.

\section{Results and Discussions}

6.1 Respondents' demographic profile.

Table.2. Respondents Sample according demographic variables

\begin{tabular}{|c|c|c|c|}
\hline Gender & $\begin{array}{c}\text { No. of } \\
\text { Respondents }\end{array}$ & $\begin{array}{c}\text { Total } \\
\text { Population }\end{array}$ & Percentage $\%$ \\
\hline Male & 44 & \multirow[t]{16}{*}{70} & 62.9 \\
\hline Female & 26 & & 37.1 \\
\hline \multicolumn{2}{|c|}{ Age (in years) } & & \\
\hline $20-30$ & 30 & & 42.85 \\
\hline $31-40$ & 25 & & 35.71 \\
\hline $41-50$ & 12 & & 17.14 \\
\hline $51-60$ & 3 & & 4.28 \\
\hline \multicolumn{2}{|c|}{ Educational level } & & \\
\hline Diploma level & 15 & & 22.6 \\
\hline Bachelor degree & 36 & & 51.42 \\
\hline Master's degree & 12 & & 17.14 \\
\hline PhD degree & 7 & & 10 \\
\hline \multicolumn{2}{|c|}{ designation } & & \\
\hline Managers & 10 & & 14.3 \\
\hline assistant & 8 & & 11.4 \\
\hline Non-Managers & 52 & & 74.2 \\
\hline
\end{tabular}

The results provided in table (2) indicate that the highest percentage of personnel sample was for males of $(62.2 \%)$ while the percentage of females are $(37.1 \%)$ of the sample total. This indicates that the majority of staffs at National Bank of Bahrain are male and from various functional levels. Could be due to the biological responsibility of childbearing and temporarily moving away their careers in order to make room for family obligations. Also, the above table shows that 30 respondents representing $42.85 \%$ and their ages are between of 20 t0 30 years. And 25 respondents their ages between of 31 to 40 years, representing $35.71 \%$. Whereas 12 respondents their ages are between the age ranges of 41 to 50 years formed $17.14 \%$ percent of the sample total 70 respondents. Only three respondents are between ages of 51 to 60 representing $4.28 \%$. This reveals 
that the bank polices are concentrated on youthful people class. Finally, the respondents gave details of their current position, and it was found that most of managers' respondents and their assistant are between ages range of (41-50) and (51-60), and these class are belonging to the group of mature ages, who they have a high experience and qualified to rise to managerial positions.

\section{2 descriptive analysis}

In order to have a clear interpretation, and give a good perception, understanding of the variables, and to summarize all trends in the collected data, the researcher using the descriptive analysis as shown in Table 3, including the means, standard deviations, and minimum and maximum values that have been measured on a five-point Likert scale to address the questionnaire items comprised of Strongly Agree, Agree, Neutral, Disagree, and Strongly Disagree. Mean scores of less than 2.50 were considered low, mean scores were considered moderate between 2.50 - 3.80, while mean scores of more than 3.80 is considered strong. And the values for Cronbach Alpha are greater than 0.60 .

Table 2. Arithmetic Means and Standard Deviations for the Study Variables dimensions

\begin{tabular}{|l|c|c|c|c|}
\hline Variables & Mean & $\begin{array}{c}\text { Standard } \\
\text { Deviation }\end{array}$ & Minimum & Maximum \\
\hline $\begin{array}{l}\text { Planning Job } \\
\text { Analysis }\end{array}$ & 3.985 & 0.586 & 1 & 5 \\
\hline $\begin{array}{l}\text { Recruitment } \\
\text { Selection }\end{array}$ & 3.893 & 0.685 & 2 & 5 \\
\hline $\begin{array}{l}\text { Training and } \\
\text { Development }\end{array}$ & 3.855 & 0.779 & 1 & $\underline{5}$ \\
\hline $\begin{array}{l}\text { Compensation } \\
\text { (Pay and } \\
\text { Benefits) }\end{array}$ & 3.720 & 0.808 & $\underline{2}$ & $\underline{5}$ \\
\hline $\begin{array}{l}\text { Competitive } \\
\text { Advantage }\end{array}$ & 3.692 & 0.627 & $\underline{1.5}$ & $\underline{5}$ \\
\hline
\end{tabular}

The descriptive analysis in table 2 Showed that the arithmetical mean and the standard deviation for the trends of the study sample about the statements of study related to the HRM practices variables were positive. And arithmetic means of the variables' phrases are higher than the average level (3), pointing out that the sample study agrees to these statements with a high percentage, as the average comes between (3.720-3.893), whereas the standard deviation average comes between (0.586- 0.808). Thus, the arithmetical mean of Planning Job Analysis coming in the first rank with (3.985), while the arithmetical mean of Recruitment Selection coming in the second rank with (3.893), and the arithmetical mean of Training and Development is coming in the third rank with (3.855), whereas and finally, the Compensation (Pay and Benefits) comes at the final stage with (3.720). This indicated that the mean values for all study dimensions were higher than the midpoint point level (3) of the Likert scale (5) points. These outcomes emphasized that respondents' perceptions with regard to the study's variables were up of the average, as well the standard deviation results appeared that there is no significant difference in the views of the sample toward the HRM practices towards the Sustainable Competitive Advantage. Finally, the results indicated that respondents positively responded, about the role of HRM practices towards Sustainable Competitive Advantage in National Bank of Bahrain.

\subsection{Hypothesis testing}

In the light of indications in the conceptual framework, the study seeks to achieve its goals and embodiment of its importance, through examining the hypotheses, simple linear regression test and unilateral variation analysis (ANOVA) was used to measure the impact of independent variables in the dependent variable. The positive hypotheses were developed as follows: 


\subsubsection{Testing the Main Hypothesis}

H1: HRM Practices affect the achievement of a competitive advantage in the National Bank of Bahrain.

After applying the linear regression on the collected data to test the cause and effect relationship between the HRM practices (independent variable) and between the Competitive Advantage (dependent variable) so the result of the main hypothesis was drawn, and the likelihood of statistics show the significance of the research. According to the standard if the pvalue is $(<0.05)$ it is significant.

Table 4. Results of the main hypothesis Testing

\begin{tabular}{|c|c|c|c|c|c|c|c|c|}
\hline $\begin{array}{c}\text { Variation } \\
\text { Source }\end{array}$ & $\begin{array}{c}\text { Total } \\
\text { Squares }\end{array}$ & $\begin{array}{l}\text { Freedom } \\
\text { Degrees }\end{array}$ & $\begin{array}{c}\text { Ave. } \\
\text { Squares }\end{array}$ & $\begin{array}{c}\text { Correlation } \\
\text { Coefficient } \\
\text { R }\end{array}$ & $\begin{array}{c}\text { Determination } \\
\text { Coefficient } \\
\text { R2 }\end{array}$ & $\begin{array}{l}\text { Calculated } \\
\text { value }(\mathrm{T})\end{array}$ & $\begin{array}{c}\text { Test } \\
\text { Value } \\
\text { F }\end{array}$ & $\begin{array}{c}\text { Sig } \\
\text { F }\end{array}$ \\
\hline Regression & 38.48 & 1 & 15.10 & \multirow[t]{3}{*}{$0.580(a)$} & \multirow[t]{3}{*}{0.348} & 15.963 & \multirow[t]{3}{*}{102.116} & \multirow[t]{3}{*}{$.000(a)$} \\
\hline Residual & 56.20 & 244 & 0.135 & & & 10.116 & & \\
\hline Total & 87.68 & 245 & & & & & & \\
\hline
\end{tabular}

Table 4 shows that the independent variable of the study HRM practices has a statistically significant influence on the Competitiveness Advantage as the dependent variable. Based on the high value of the calculated (F) equal to (102.116) and the value of the statistical significance (Sig) of $(0,000)$, which is less than the level of significance $(a=0.05)$ This means that the model is validated for hypothesis testing.

The correlation coefficient value (R) of (0.580(a)) shows that there is a positive statistically significant effect at the significance level ( $\alpha=$ 0.05 ) between the HRM practices and between competitive advantage, this is confirmed by the calculated (T) values of (10.116). In addition, the value of the statistical significance ( $\mathrm{Sig}$ ) is less than the level of significance $((a=0.05)$.
In addition, the Determination Coefficient R2 interpret that the HRM Practices interpret a ratio of $(34.8 \%)$ of the variance that could occur on the competitive advantage as dependent variable, which indicates the significance size of the effect of the independent variable in dependent variable to gain the competitiveness, while the remaining ratio of $(65.2 \%)$ is attributed to other variables not included in the Simple linear regression model. In light of the previous results, the main hypothesis will be accepted which states that the regression is considerably and consequently: HRM Practices have a significant influence on achieving a competitive advantage in the National Bank of Bahrain.

\begin{tabular}{|c|c|c|c|c|c|c|c|c|}
\hline $\begin{array}{l}\text { Variation } \\
\text { Source }\end{array}$ & $\begin{array}{l}\text { Total } \\
\text { Squares }\end{array}$ & $\begin{array}{l}\text { Freedom } \\
\text { Degrees }\end{array}$ & $\begin{array}{l}\text { Ave. } \\
\text { Squares }\end{array}$ & $\begin{array}{l}\text { Correlation } \\
\text { Coefficient } \\
\mathrm{R}\end{array}$ & $\begin{array}{l}\text { Determination } \\
\text { Coefficient( } \\
\text { R2 }\end{array}$ & $\begin{array}{l}\text { Calculated } \\
\text { value }(\mathrm{T})\end{array}$ & $\begin{array}{l}\text { Test } \\
\text { Value } \\
\text { F }\end{array}$ & $\begin{array}{l}\text { Sig } \\
\text { F }\end{array}$ \\
\hline Regression & 18.185 & 1 & 16.10 & 0.560 (a) & 0.388 & 17.863 & 104.112 & $.000(a)$ \\
\hline Residual & 48.288 & 246 & 0.155 & & & 12.110 & & \\
\hline Total & 57.687 & 248 & & & & & & \\
\hline
\end{tabular}


Table "5" shows a high value of calculated (F) equal to (104.112), which is significant at the level of significance 0.01 and confirmed by the value of correlation coefficient (0.560 (a)). Based on the value of the coefficient of determination $\mathrm{R} 2=(0.388)$, the variation in human resources management practices interpret $(38.8 \%)$ of the variation in a competitive advantage, and according to this result, Planning and Job Analysis have a statistically significant impact of reaching the competitive advantage in the National Bank of Bahrain.

In the light, the study accepted the hypothesis which said that:

- the effect size of the change independent variable in the dependent variable

- The employees become aware of that the planning and Job Analysis has a positive predictive strength for accomplishing the competitive advantage.

H1.2: Recruitment Selection affect the achievement of a competitive advantage in the National Bank of Bahrain

Table 6. Result of Testing the forth Sub- Hypothesis

\begin{tabular}{|c|c|c|c|c|c|c|c|c|}
\hline $\begin{array}{l}\text { Variation } \\
\text { Source }\end{array}$ & $\begin{array}{c}\text { Total } \\
\text { Squares }\end{array}$ & $\begin{array}{l}\text { Freedom } \\
\text { Degrees }\end{array}$ & $\begin{array}{c}\text { Ave. } \\
\text { Squares }\end{array}$ & $\begin{array}{c}\text { Correlation } \\
\text { Coefficient } \\
\text { R }\end{array}$ & $\begin{array}{c}\text { Determination } \\
\text { Coefficient } \\
\text { R2 }\end{array}$ & $\begin{array}{l}\text { Calculate } \\
\text { d value } \\
\text { (T) }\end{array}$ & $\begin{array}{c}\text { Test } \\
\text { Value } \\
\text { F }\end{array}$ & $\begin{array}{l}\text { Sig } \\
\text { F }\end{array}$ \\
\hline Regression & 21.216 & 1 & 4.10 & 0.601 (a) & 0.341 & 16.221 & 13.82 & 0.000 \\
\hline Residual & 32.632 & 247 & 0.28 & & & 11.321 & & \\
\hline Total & 53.848 & 248 & & & & & & \\
\hline
\end{tabular}

Table (6) shows pointed out the independent variable had a statistically significant effect in the dependent variable based on the high value of $(\mathrm{F})$ calculated (13.82) and the value of statistical significance of ( $\mathrm{Sig})$ is (0.000), which is less than the $(\alpha>0.05)$. This means proving the validity of the model to test the hypothesis, Thereby, we can conclude that Recruitment Selection plays a positive role on gaining a competitive advantage in the National Bank of Bahrain ". The table also shows that the correlation coefficient value (R) is $(0.601(\mathrm{a}))$, which indicates a positive relationship with statistically significant at Level $(\mathrm{a}=0.05)$ between HRM
Practices and between a sustainable competitive advantage. And this confirmed by the value of correlation coefficient $\mathrm{R}$ (0.601 (a)). Based on the value of the coefficient of determination $\mathrm{R} 2=(0.341)$, the variation in the Recruitment Selection interpret $(34.1 \%)$ of the variation in a competitive advantage, and according to this result, the study accepted the hypothesis which said "Recruitment Selection affect the achievement of a competitive advantage in the National Bank of Bahrain."

H1.3: Training and Development affect the achievement of a competitive advantage in the National Bank of Bahrain.

Table 7. Result of Testing the third Sub- Hypothesis

\begin{tabular}{|c|c|c|c|c|c|c|c|c|}
\hline $\begin{array}{l}\text { Variation } \\
\text { Source }\end{array}$ & $\begin{array}{l}\text { Total } \\
\text { Squares }\end{array}$ & $\begin{array}{l}\text { Freedom } \\
\text { Degrees }\end{array}$ & $\begin{array}{l}\text { Ave. } \\
\text { Squares }\end{array}$ & $\begin{array}{l}\text { Correlation } \\
\text { Coefficient } \\
\mathrm{R}\end{array}$ & $\begin{array}{l}\text { Determination } \\
\text { Coefficient } \\
\text { R2 }\end{array}$ & $\begin{array}{l}\text { Calculat } \\
\text { ed value } \\
(\mathrm{T})\end{array}$ & $\begin{array}{l}\text { Test } \\
\text { Value } \\
\text { F }\end{array}$ & $\begin{array}{l}\text { Sig } \\
\text { F }\end{array}$ \\
\hline Regression & 25.316 & 1 & 5.10 & \multirow[t]{3}{*}{0.641 (a) } & \multirow[t]{3}{*}{0.412} & 18.221 & \multirow[t]{3}{*}{14.216} & \multirow[t]{3}{*}{0.000} \\
\hline Residual & 32.432 & 240 & 0.35 & & & 13.321 & & \\
\hline Total & 56.848 & 241 & & & & & & \\
\hline
\end{tabular}

Table (7) shows pointed out the independent variable had a statistically significant effect in the dependent variable based on the high value of $(F)$ calculated (14.216) and the value of statistical significance of ( $\mathrm{Sig})$ is (0.000), which is less than the $(\alpha>0.05)$. This means proving the validity of the model to test the hypothesis, Thereby, we can conclude 
that Training and Development plays a positive role on gaining a competitive advantage in the National Bank of Bahrain ". The table also shows that the correlation coefficient value $(\mathrm{R})$ is $(0.641(\mathrm{a}))$, which indicates a positive relationship with statistically significant at Level $(a=0.05)$ between HRM Practices and between a sustainable competitive advantage. And this confirmed by the value of correlation coefficient R (0.641 (a)). Based on the value of the coefficient of determination $\mathrm{R} 2=(0.412)$, the variation in the Recruitment Selection interpret $(41.2 \%)$ of the variation in a competitive advantage, and according to this result, the study accepted the hypothesis which said "Training and Development affect the achievement of a competitive advantage in the National Bank of Bahrain ".

H1.4: Compensation (Pay and Benefits) affect the achievement of a competitive advantage in the National Bank of Bahrain.

Table 8. Result of Testing the second Sub- Hypothesis

\begin{tabular}{|c|c|c|c|c|c|c|c|c|}
\hline $\begin{array}{c}\text { Variat } \\
\text { ion } \\
\text { Sourc } \\
\text { e }\end{array}$ & $\begin{array}{c}\text { Tot } \\
\text { al } \\
\text { Squ } \\
\text { ares }\end{array}$ & $\begin{array}{l}\text { Free } \\
\text { dom } \\
\text { Degr } \\
\text { ees }\end{array}$ & $\begin{array}{l}\text { Ave. } \\
\text { Squ } \\
\text { ares }\end{array}$ & $\begin{array}{c}\text { Correl } \\
\text { ation } \\
\text { Coeffi } \\
\text { cient } \\
\text { R }\end{array}$ & $\begin{array}{c}\text { Determi } \\
\text { nation } \\
\text { Coeffici } \\
\text { ent } \\
\text { R2 }\end{array}$ & $\begin{array}{l}\text { Calcu } \\
\text { lated } \\
\text { value } \\
\text { (T) }\end{array}$ & $\begin{array}{c}\text { Tes } \\
t \\
\text { Val } \\
\text { ue } \\
\mathrm{F}\end{array}$ & $\begin{array}{c}\text { Sig } \\
\mathrm{F}\end{array}$ \\
\hline $\begin{array}{l}\text { Regre } \\
\text { ssion }\end{array}$ & $\begin{array}{c}31.4 \\
8 \\
\end{array}$ & 5 & 5.10 & \multirow[t]{3}{*}{$\begin{array}{l}0.540 \\
\text { (a) }\end{array}$} & \multirow[t]{3}{*}{0.338} & $\begin{array}{c}17.96 \\
3 \\
\end{array}$ & \multirow[t]{3}{*}{$\begin{array}{l}10 . \\
116\end{array}$} & \multirow[t]{3}{*}{$\begin{array}{l}0.0 \\
00\end{array}$} \\
\hline $\begin{array}{c}\text { Resid } \\
\text { ual }\end{array}$ & $\begin{array}{l}58 . \\
20 \\
\end{array}$ & 190 & $\begin{array}{c}0.3 \\
5 \\
\end{array}$ & & & $\begin{array}{c}10.4 \\
66 \\
\end{array}$ & & \\
\hline Total & $\begin{array}{c}89 . \\
68\end{array}$ & 195 & & & & & & \\
\hline
\end{tabular}

Table (8) clarified out the independent variable had a statistically significant effect in the dependent variable based on the high value of $(F)$ calculated (10.116) and the value of statistical significance of ( $\mathrm{Sig}$ ) is (0.000), which is less than the $(\alpha>0.05)$. This means proving the validity of the model to test the hypothesis, Thereby, we can conclude that Compensation (Pay and Benefits) plays a positive role on gaining a competitive advantage in the National Bank of Bahrain ". The table also shows that the correlation coefficient value $(R)$ is $(0.641(a))$, which indicates a positive relationship with statistically significant at Level $(a=0.05)$ between HRM Practices and between a sustainable competitive advantage. And this confirmed by the value of correlation coefficient R (0.540 (a)). Based on the value of the coefficient of determination $\mathrm{R} 2=(0.338)$, the variation in the Compensation (Pay and Benefits) interpret (33.8\%) of the variation in a competitive advantage, according to this result, the study accepted the hypothesis which said "Compensation (Pay and Benefits) affect the achievement of a competitive advantage in the National Bank of Bahrain

\section{7-Discussion}

The aim of this paper is to investigate the effect of HRM practices on Sustainable Competitive Advantage in the National Bank of Bahrain. The quantitative data gathered from the study society, and employed to test the study hypotheses, which produced meaningful results represent the employees' perception of the four dimensions of HRM practices. The respondents' responses indicated the variables of "Planning Job Analysis, and training, development", came at the first rank, whereas Compensation and Recruitment Selection have got moderate levels of respondents' responses, as shown at Table 1.

The literature studies indicate that HRM activities such as planning Job Analysis, training and development, and Compensation have a maximum significance at the organizations. It's the mechanism by which the organization seeks to fulfill workforce needs are properly met, and kept them, sustained, trained, well-educated created, stabilized and morally enhanced (Lee and Bruvold, 2003; Masoodul et al., 2013; Eric et al., 2012; David et al., 2015; Dessler, 2015.

Furthermore, according to the effect dimensions of HRM practices on the competitive advantage the findings detected that there is a statistically significant impact of HRM practices dimensions on the Planning and Job Analysis, selection and recruitment, training and development, and Compensation (Pay and Benefits) on the competitive Advantage, as the Planning and Job -Analysis variable coming in the first rank with arithmetical Mean (3.985) and standard deviation (0.586), as shown in Table 4.

In the table (2) regarding, the impact of the dimensions of planning and Job Analysis, and Recruitment and Selection, the results revealed that there is a statistically significant impact of these dimensions on Competitive Advantage, and indicated that the planning and recruitment and selection processes within JIB are well defined, and the staff perceived and knowing well the rules and procedures and having high experience and knowledge in the recruitment and selection process for employees, so these variables got the highest arithmetical mean score, and respectively(3.985), (3.893).

Generally, this study presents interpretations of the views of manpower on human resources activities and their effect on the competitive advantage. In this field, we can say that there is a necessity to increase the awareness and the understanding about the significance of human resource management practices, and the competitive advantage importance, besides with finding an adequate regulatory environment allow the principles of competitive advantage 
to be adopted and implemented of it in the National Bank of Bahrain.

\section{8-Conclusions}

After presenting, analyzing, and discussing the study results in the light of the hypotheses, the study reached a set of conclusions regarding the impact of human resource management practices on building a competitive advantage in the National Bank of Bahrain, which can be summarized as follows:

1- This research investigates the influence of human resource management practices in achieving a competitive advantage. The findings detected that the dimensions of human resource management practices which including, planning Job Analysis, Recruitment Selection, Training and Development, and compensation (Pay and Benefits) have a major effect, and high participation in achieving competitive advantage to National Bank. The results, also supported the hypothesis that human resources management practices adopted in the National Bank of Bahrain significantly effect on attain a sustainable competitive advantage. Consequently, sustainable competitive advantage in in the National Bank is greatly influenced by human resource management activities, and this was proved by the study sample introduced. Thus the four human resource management practices implemented have a direct effect on enhancing the performance of National Bank significantly effect on attain a sustainable competitive advantage performance. Thus, this paper will contribute through theoretical literature to bridges the gap between theory and practice in identifying new empirical evidence on human resources management practices and a sustainable competitive advantage.

2- The National Bank of Bahrain gives great consideration to the human resource management practices, so the study dimensions as follows, human resource planning and job analysis came in the first stage, while procedures for the recruitment and selection process in the second stage, and Training and Development human resources in the third place, then focus on and compensation (Pay and Benefits) in the rank Fourth.

3-

Human resource management is considered one of the most significant and critical departments in this study because human resource management practices have a strategic dimension focused on the achievement of the institution's objectives, and in front is achieving a sustainable competitive advantage that provides the bank an advanced position by presenting high-quality services that could meet both the institution's objectives and fulfill the needs and desires of customers.

4-

RM acts towards being an essential element in the overall function of an organization. In this approach, individuals are perceived as a crucial resource. HRM is characterized as the process of planning Job Analysis, Recruitment Selection, evaluating and managing the human resources needs of an organization to ensure its strategic objectives are achieved. The purpose of HRM's function is to plan, evolve and monitor policies, practices, and strategies that developed so as to enlarge HR utilizations. This aspect of management reflects and concentrates on the workers within the company and their relationships. So, HRM holds a very important place, as the study indicates that human capital can be a competitive and advantageous source and that HR has the most effectiveness, and the dynamic existence of HRM practice structures will foster the chance to compete to gain a competitive advantage.

$5-$

he added value of HRM in the business depends on the way that implements its practices, along with its operation and functions. Upon that, HRM can add value at any point of the process of its activities, the way and time the HR is included in the critical procedures are as an important basis in identity to add value for the HR, and this could reflect on increasing a chance for the organization getting a competitive advantage.

6-

$\mathrm{n}$ order to determine the importance of HRM practices in obtaining Competitive Advantage, a questionnaire was used to test the role of HRM in increasing the competitive advantage in the case of 
the National Bank of Bahrain. The questionnaire gathered information about employee perceptions and opinions; about the bank and HRM practices related to Planning Job Analysis, Recruitment Selection, Training and Development, and Compensation (Pay and Benefits). A standardized questionnaire consisting of 39 questions was used in the quantitative survey. The key purpose of qualitative research was to better understand the research topics provided with the National Bank of Bahrain's HRM practices. According to the findings, the respondents are most contented with the performance of the recruitment and planning process in the bank. The respondents are mainly unsatisfied with HR's encouragement incentives and remuneration practices systems. For a better analysis of National Bank's HRM practices, the competitive advantage of globalization variables and the varied organizational employees means that National Bank of Bahrain is on the right track and able to compete on the internal and external business market.

7-

With reference to previous studies and there is consensus on the findings and recommendations of the study "The effect of training on employee performance A Case Study of District Five Administration Office, Bole Sub-City, Addis Ababa, Ethiopia"((Elnaga, A, \& Imran, A. 2013)), the researcher concluded in his study that the results of the materials and the appropriate training and tools compatible with the training that will contribute to increasing the level of performance, the researcher recommended in his study the necessity to use the modern tool and training materials matching with the narrative of the technological development which could contribute to getting a competitive advantage.

$8-$

ith reference to previous studies and there is and consensus on the findings and recommendations of the study "Pfeffer (1994) has put out sixteen practices if applied in the right method could lead to achieving Sustainable competitive advantage through the human resources practices of which: Incentive pay, Participation, and empowerment, Training and skill development, etc.), the researcher concluded in his study that the results of these Practices and others, will affect the employee's performances' and pushing them towards achieving Sustainable competitive advantage.

9-

inally, the competitive advantage has thus become a must for HRPs and the in the National Bank of Bahrain Top Management Team. Including establishing an Integrated Employee Culture, through encouraging and support empowering employees and developing their skills, involving them in decisions. Creating a culture of continuous learning and development. Continuously building an organizational culture that also supports its strategic goals and serves its organization by becoming an expert and a professional in their work, thus enabling them to participate in achieving their organization's competitive advantage. This article contributed to the body of the knowledge in the financial institutions. Theoretically, this article provided facts about the practices of human resource management practices and that may lead to improving the employees' participation towards sustainable competitive advantage. Concurrently, it has a significant contribution towthe practitioners in the financial firms in the role of the HRM in encouraging and enhancing the employees' participation in strategies planning.

\section{Reference}

[1]. Scherer, G. Palazzo, and D. Seidl, Journal of Management Studies 50, 259?284, (2013). Doi: 10.1111/joms. 12014

[2]. Bakker A.B., Demerouti E., 2008, Towards a Model of Work Engagement, Career Development International, 13(3).

[3]. Barney, J. (1991). Firm Resources and Sustained Competitive Advantage. Journal of Management, 17(1), pp. 99-120.

[4]. Barney, Jay. (1991). "Firm Resources and Sustained Competitive Advantage." Journal of

[5]. Bo, H. (2007). Company-based determinants of training and the impact of training on company performance: Results from an international HRM survey. Personnel Review, 36(2), 311-331. DOI 10.110800483180710726163

[6]. Bowra, Z., Sharif B., Saeed A., \& Niazi, M. (2012). Impact of human resource practices on employee perceived performance in banking sector of Pakistan. African Journal of Business Management, 6(1), 323-332.

[7]. Bowra, Z., Sharif B., Saeed A., \& Niazi, M. (2012). Impact of human resource practices on employee 
perceived performance in banking sector of Pakistan. African Journal of Business Management, 6(1), 323-332

[8]. Brockbank ,w,(2009). If HR were Really Strategically Proactive: Present and Future Directions in HR's Contribution to Competitive Advantage, Human Resource Management. Vol, 38, No, 4.

[9]. David P.C., Nikki B., Meredith R.C., Jamie B.S., Arwen H.D., 2015, The Effect of Adaptive Organizational Culture on Long-Term Survival, "Journal of Business and Psychology", 31(3).

[10]. Dessler G., 2015, Human Resource Management, Global Edition (14 ed.), Essex: Pearson Education Limited.

[11]. Dessler,G.(2007). Human resource management. USA: Prentic Hall.

[12]. Diefendorff J.M., Chandler M.M., 2011, Motivating Employees, [In:] S. Zedeck (Ed.), Handbook of industrial and organizational psychology, Washington, DC: American Psychological Association.

[13]. Elnaga, A, \& Imran, A. (2013). The effect of training on employee performance. European Journal of Buisness and Management, 5(4), 137147.

[14]. Eric Ng C.H.E., Lam Z.H., Ramesh K., Charles R., Vimala K., 2012, An Effectiveness of Human Resource Management Practices on Employee Retention in Institute of Higher learning: A Regression Analysis Article, "International Journal of Business Research and Management (IJBRM)", 3(2).

[15]. Fattler,M, (2009). Achieving Competitive Advantage through Strategic Human Resource Management, Hospital\& Health Service Administration, VOL1,35. No 3.

[16]. Faugoo, D. (2009). Globalization and Its Influence on Strategic Human Resource Management, Competitive Advantage and Organizational Success. International Review of Business Research Papers, 5(4), pp. 123-133.

[17]. Harel, G.H. and Tzafrir, S.S. 1996. "The Effects of Human Resource Management Practices on the Perceptions of Organisational and Market Performance of the Firm", Human Resource Management, 38, pp.185-200.

[18]. Hoffman, N. P. (2000). An examination of the" sustainable competitive advantage" concept: past, present, and future. Academy of Marketing Science Review, 4(2000), 1- 16.Available at http://www.amsreview.org/articl es/hoffman042000.pdf.

[19]. Huselid, M.A. 1995. "The Impact of Human Resource Management Practices on Turnover, Productivity, and Corporate Financial Performance", Academy of Management Journal, 38(3),pp. 635-672.

[20]. K. Hafeez, Y. Zhang, and N. Malak, IEEE Transaction on Engineering Management49, $28 ? 35$ (2002).

[21]. Katou, A., and Budhwar, P. 2006. "The Effect of Human Resource Management Systems onOrganizational Performance: Test of a Mediating Model", International Journal of HumanResource Management, 17(7), pp. 12231253.

[22]. Lado, A.A., Wilson, M.C., 1994. Human resource systems and sustained competitive advantage: a competency-based perspective.Academy of Management Journal 19 (4), 699-727

[23]. Lee C.H., Bruvold N.T., 2003, Creating Value for Employees: Investment in Employee Development, "International Journal of Human Resource Management”, 14(6).

[24]. Lee, K., \& Carter, S. (2011). Global marketing management. Strategic Direction, 27(1).

[25]. M. Hitt, D. Ireland, and R. Hoskisson, 2009, Strategic Management: Competitiveness and Globalization, Volume 8th, South-Western Cengage Learning, Ohio, 2009.

[26]. Maha A.Z.D., 2015, The Impact of Employee Engagement on Job Performance and Organizational Commitment in the Egyptian Banking Sector, "Journal of Business and Management Sciences", 3(5).

[27]. Management 17 (1): 99-120

[28]. Marques, J. (2007). HR in all its glory. Human Resource Management International Digest, 15(5), 3-6.

[29]. Masoodul H., Saad H., Muhammad F.A.K., Asghar I., 2013, Impact of HR Practices on Employee Satisfaction and Employee Loyalty: An Empirical Study of Government Owned Public Sector Banks of Pakistan, "Middle East Journal of Scientific Research", 16(1).

[30]. Muhammad A.Q., 2015, Human Resource Practices in Pakistan Banking Sector: A Conceptual Framework Including Personality Traits, Emotional Intelligence and Employee Performance, "International Journal of Scientific and Research Publications",5(1). 
[31]. Nehles A.C., Van Riemsdijk M., Kok I., Looise J.K., 2006, Implementing Human Resource Management Successfully: A First-Line Management Challenge, Management Review, 34.

[32]. O’Reilly., Charles, A. \& Pfeffer, J. (2000). Hidden Value: How Great Companies Achieve Extraordinary Results with Ordinary People, Boston: Harvard Business School Press.

[33]. Parry.E , \& Tyson. S. (2008). An analysis of the use and success of online recruitment methods in the UK Human Resource Management Journal, 18,257-274.

[34]. Pfeffer, J. (1994a). Competitive Advantage through People.California Management Review, Winter, pp. 9-28.

[35]. Porter, 1998 Creating and Sustaining Superior Performance Michael E. Porter Free Press, 1998.

[36]. Porter, M. (1985). Competitive Advantage: Creating sustaining Superior Performance, New York: Free Press.

[37]. Porter. M.E (1985). Competitive Advantage: Creating and Sustaining Superior Performance. New York: The Free Press.

[38]. Richards, J. C. \& Schmidt, R. (2002). Longman dictionary of language teaching and applied linguistics. 3 rd . ed. London: Longman.

[39]. Schuler, R. S., MacMillan, I. C. (1984). Gaining Competitive Advantage through Human Resource Management Practices. Human Resource Management Journal, 23(3), pp. 241-255.

[40]. Sekaran, U, and Bougie R. 2010. " Research methods for business; A skill building approach". Wiley and Sons 5th Edition,. ISBN10:0470744790

[41]. Sheikh, Fouad Najib (2004), The Relationship between Information Systems and the Competitive Advantage in the Jordanian Pharmaceutical Sector, Journal of Public Administration, Volume (44), No. (p).

[42]. Shen, J. \& Edwards, V., (2004). "Recruitment and Selection in Chinese MNEs", International Journal of Human Resource Management, Vol. 15, No. 4, pp. 814-835.

[43]. Som, A. (2003). Redesigning the Human Resources Functions at Lafarge. Human Resource Management, 42(3), pp. 271-288.

[44]. T. Wheelen and D. Hunger, Strategic Management and Business Policy: Toward Global Sustainability, Volume 13th, Pearson Education, Inc. Boston, 2012. ISBN-13: 978-0-13-215322-5 ISBN-10: 0-13-215322-X
[45]. Tripathi, P. C. (2002). Human resources development. New Delhi: Sultan Chand\& Sons.

[46]. Walker,J.W.(1980). Human Resource Planning. New York: McGraw-Hill. Ibid.

[47]. Yingying L., 2017, Review of Human Resource Management Function of Front Line Managers, "Open Journal of Business and Management", 5(4). 